\title{
Towards a methodology for the use of geo-information technology in disaster assessment
}

\author{
Dawie van Vuuren
}

\section{Introduction}

Disaster assessment entails the description of disaster events and their impact on human lives, property and the environment. Information is a vital component of this process, and geo-information technology in particular should have a key role in this regard.

Data associated with disasters is inherently spatial, and geo-information technology (G-IT) has been shown to be central to the integration, analysis, visualization, knowledge generation and communication during an event (Ahearn et al, 2006). Whereas geo- information technology is readily available, it still appears to be underutilised, especially in the case of events occurring in a small geographical area, or events with a lesser impact (Smith, 2001).

Ahearn et al, (2006), Guha-Sapir \& Below (2006), and Smith, (2001) mention a number of factors contributing to the lack of G-IT application. These can be grouped into two categories: institutional problems and technical problems.

Institutional problems include the following:

- The capturing of data on disaster occurrence is not institutionalised;

- There is a lack of standardised data collection methodologies;

- The pressure to respond quickly for fund raising or relief planning is usually paramount;

- Prevention planning and community preparedness programmes are rarely funded;

- The costs of hazard mapping and detailed inventories are perceived to be high. 
Technical problems include:

- lack of suitable software in place;

- lack of human resources dedicated to G-IT functions;

- lack of suitable training;

- lack of understanding of the technology by responders (DRM officials);

- a disconnect between the producers of geospatial data and the consumers of it;

- the existence of data gaps, scale inconsistencies, and data currency;

- Lack of meta-data.

The lack of available data in respect of disasters is singled out as a major weakness for long-term planning (Guha-Sapir \& Below, 2006). To address this, a methodology for the sustainable application of G-IT in disaster assessment should be developed. An opportunity to establish a research project for this purpose was identified shortly after the floods that occurred in the Southern Cape in July 2006.

\section{The Research Project}

The research project, registered with the African Centre for Disaster Studies (ACDS) at North-West University in South Africa (Potchefstroom Campus), is based on a desktop study of relevant literature, a practical exercise and an analysis of information. This paper focuses on the practical component of GIS activities to demonstrate the value of a GIS-based methodology.

\section{Problem Statement}

As indicated above, there is a lack of well structured geo-referenced data on disaster events. The most comprehensive weather related hazard dataset to date, which is publicly available in South Africa, has been developed by the South African Weather Service. This is generally referred to as the 'Caelum' database (Poolman, 2006). This database comprises a list of notable weather events in South Africa from 1961 and is updated regularly.

Although this database is comprehensive in terms of national scale, it falls short of local differentiation, as is illustrated in Figure 1. 


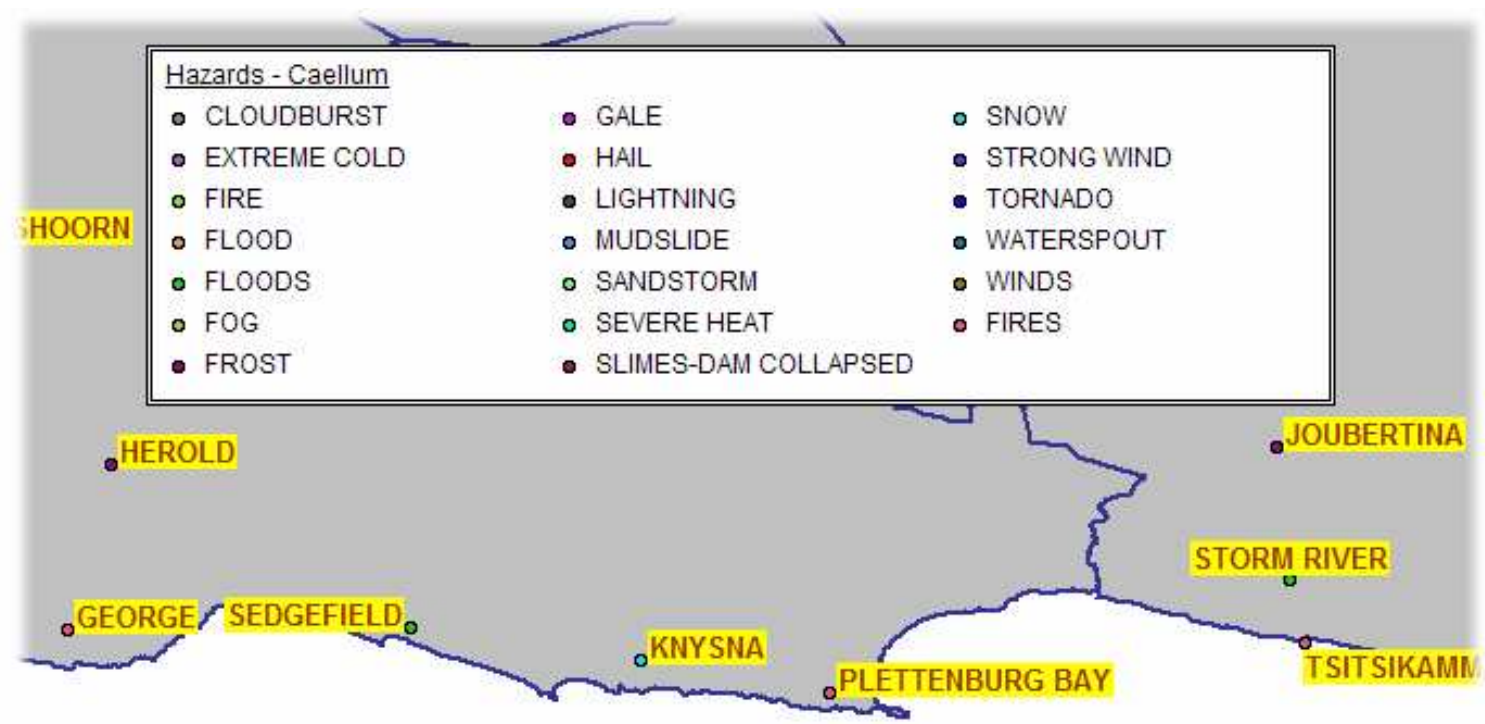

Figure 1: Map indicating the location of hazardous impact events in the Southern Cape.

Source: Caelum database, 2005. Latitude/Longitude values captured as point data in PlanetGIS.

The events in the Caelum database are linked to place names, each represented by the same latitude \& longitude coordinate for the same place. All the events in George, for example, will therefore be linked to the same location (point) on the map. As a result the differentiation between the type of hazard in George, as listed in Table 2, fails from a mapping point of view (refer to Figure 1 and Table 2). 


\begin{tabular}{|c|c|c|c|c|c|c|c|}
\hline Year & Month & Day & Hazard & Place & Latitude & Longitude & Comments \\
\hline 1964 & 09 & 16 & FLOODS & GEORGE & -34.02 & 22.38 & \\
\hline 1964 & 12 & 07 & HAIL & GEORGE & -34.02 & 22.38 & THUNDERSTORM \\
\hline 1972 & 08 & 11 & SNOW & GEORGE & -34.02 & 22.38 & \\
\hline 1981 & 05 & $\begin{array}{l}28- \\
29\end{array}$ & FLOODS & GEORGE & -34.02 & 22.38 & \\
\hline 1987 & 11 & 12 & HAIL & GEORGE & -34.02 & 22.38 & THUNDERSTORM \\
\hline 1989 & 07 & 30 & WIND & GEORGE & -34.02 & 22.38 & \\
\hline 1991 & 08 & 03 & WIND & GEORGE & -34.02 & 22.38 & \\
\hline 1992 & 10 & $\begin{array}{l}14- \\
16\end{array}$ & FLOODS & GEORGE & -34.02 & 22.38 & \\
\hline 1995 & 07 & 18 & SNOW & GEORGE & -34.02 & 22.38 & \\
\hline 1995 & 07 & 17 & SNOW & GEORGE & -34.02 & 22.38 & \\
\hline 1995 & 10 & 25 & SNOW & GEORGE & -34.02 & 22.38 & \\
\hline 1998 & 07 & $\begin{array}{l}14- \\
16\end{array}$ & FIRES & GEORGE & -34.02 & 22.38 & \\
\hline 1999 & 06 & 29 & WIND & GEORGE & -34.02 & 22.38 & \\
\hline 2003 & 03 & 25 & FLOODS & GEORGE & -34.02 & 22.38 & \\
\hline 2004 & 04 & 16 & WIND & GEORGE & -34.02 & 22.38 & \\
\hline 2004 & 12 & 22 & FLOODS & GEORGE & -34.02 & 22.38 & $\begin{array}{l}\text { EXTENSIVE } \\
\text { DAMAGE } \\
\text { PROPERTY }\end{array}$ \\
\hline
\end{tabular}

Table 1: List of events captured for George between 1964 and 2004

Source: Caelum database, 2005

Nevertheless, the data can still be analysed, and useful information produced, as illustrated in Table 2. This information should be valuable in the prioritisation of risks, and as the database is updated with more events as they occur, it will remain current and useful for continuous analysis. 


\begin{tabular}{|l|l|l|}
\hline Place & Hazard & Frequency \\
\hline GEORGE & FLOODS & 5 \\
\hline GEORGE & WIND & 4 \\
\hline GEORGE & SNOW & 4 \\
\hline GEORGE & HAIL & 2 \\
\hline GEORGE & FIRES & 1 \\
\hline
\end{tabular}

Table 2: Frequency of meteorological events in George between 1964 and 2004.

Source: Caelum database, 2005

\section{Towards a GIS-based methodology}

According to Smith (2001: 119) one of the main practical limitations to long-term planning is the lack of knowledge about location, recurrence interval and hazard potential of events which might affect small parts of urban areas. The recurrence interval of hazards can only be measured if the data describing the events have been captured in a structured database. The value of this data will be improved if the geospatial extent of events has been captured as GIS data. The development of a practical methodology for disaster assessment is based on this viewpoint.

A GIS project was created to test a methodology focused on data sourcing, data integration, data processing and data analysis for a specific study area. The study area was Glentana, a coastal town in the Southern Cape, which was severely affected by floods during July 2006. The project was conducted in five phases, and is briefly described as follows: 
1. Sourcing of baseline data for the study area and preparation for the site visit:

After defining the study area, existing cadastral data (vector) and topographical data (raster) was extracted from data archives and imported into a new GIS project. Duration: 1 Day (4 hours).

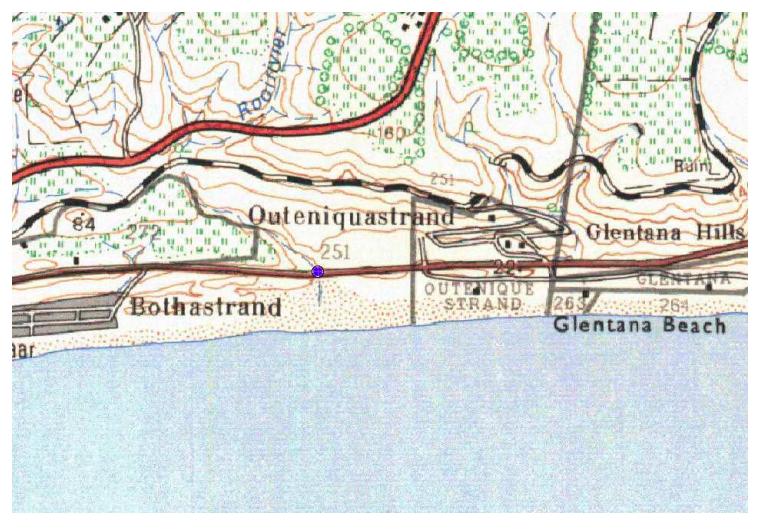

Figure 2: Example of topographical data in raster format. Source: Dept. of Land Affairs. Directorate Surveys \& Mapping

2. Site visit and data acquisition.

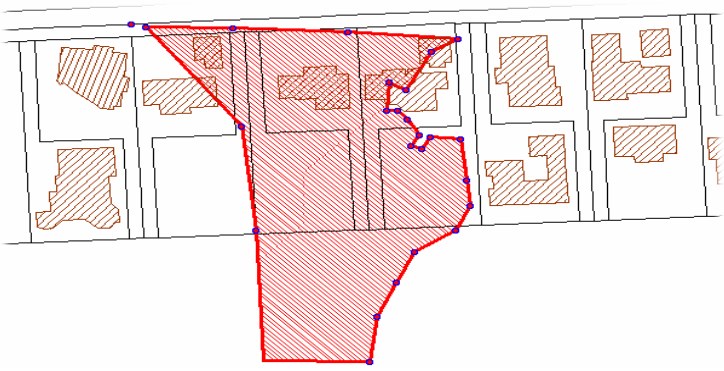

Figure 3: GPS-surveyed polygon data, overlaid on line data depicting buildings and cadastral boundaries.
A hand-held GPS was used to capture the perimeter of areas damaged by floods (two areas were chosen). The positions from where photographs were taken were also captured as point data. Duration: 2 Days (6 hours on site)

3. Sourcing and capturing of additional data:

Data on streets, buildings and contours were sourced from a company contracted by the Mosselbay municipality. Before it could be incorporated in the GIS project, it had to be processed and re-projected, since it was originally captured in a non-projected computer aided drafting (CAD) format. It was also required to capture land use data to establish the status quo of the 
study area before the floods occurred. This was done from the internet based Google Earth TM aerial photography, which was verified by interpreting photographs taken during the site visit. The land use had to be captured on the same resolution (detail level) as the acquired line data, to allow for comparable integration of the data layers.

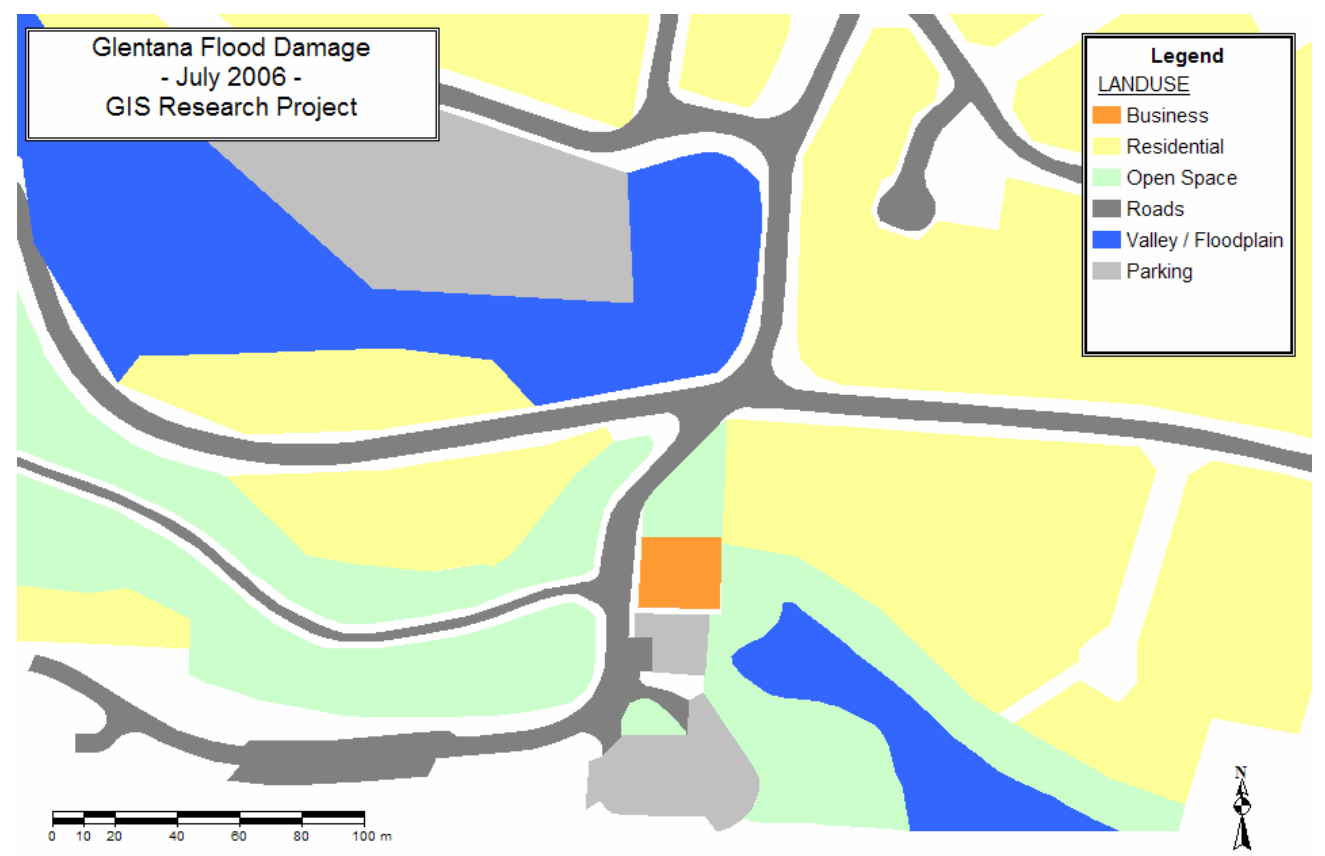

Figure 4: Land use data captured from aerial photography.

Source: Google Earth TM images.

4. An alpha-numeric database was created, consisting of the following structured tables:

- Events data (sourced from Caelum)

- Assets

- Photographs

- Land use

These data tables are linked to the spatial features in the GIS, which enhances the value of the data from an analysis perspective. It is important to note that the database is not encapsulated in the GIS project, but that it is linked by virtue of an association between spatial data features and database tables. Duration: 1 day (8 hours). 
5. Finally an analysis of all the spatial data layers that intersect with the GPSsurveyed damage area was done. A map showing some of the results was generated. It is important to note that all the information displayed on the map was generated from the integrated GIS database.

Duration: 1 day (4 hours)

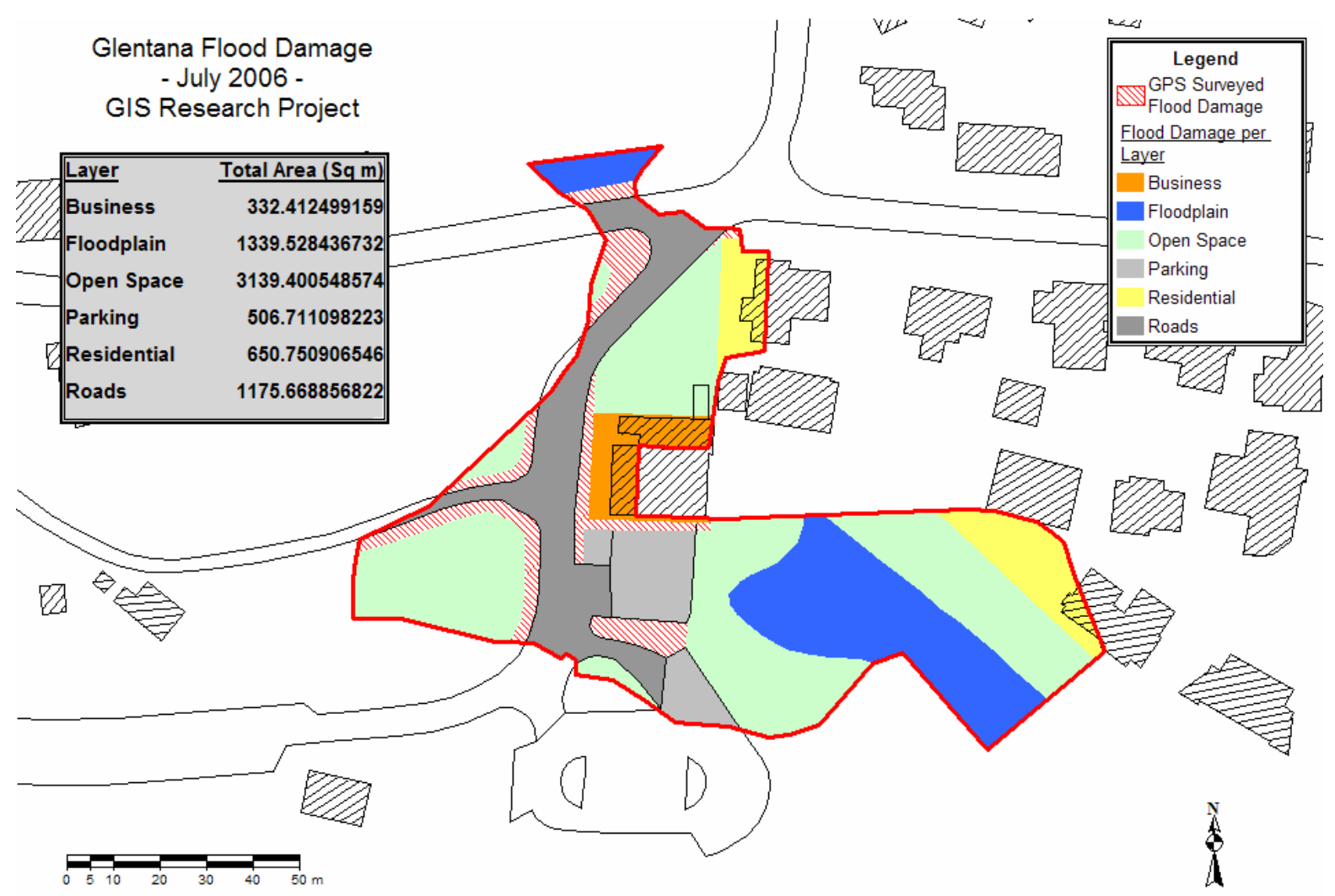

Figure 5: Results of an analysis of integrated data

\section{Summary}

The methodology is based on a cycle of GIS related activities, including data sourcing, data capturing, data processing, data analysis and visualisation. This is not a linear process, but rather a repetitive cycle of activities that are carried out in a research environment.

The focus of data management should not be in the disaster event itself, but the wider scope of development status, especially in terms of land use and infrastructure should be considered as well. 
The methodology is therefore aimed at dealing with data on the following levels:

- Pre-disaster risk reduction

- Post-disaster

- Analysis

A synthesis of data needs, data processing activities and information products is illustrated in Table 3.

\begin{tabular}{|c|c|c|}
\hline $\begin{array}{ll}\text { Pre-Disaster } & \text { Risk } \\
\text { Reduction Data } & \end{array}$ & Post-Disaster Data & Analysis \\
\hline Baseline & Location of disaster & Data integration \\
\hline - Cadastral & Extent of disaster & Spatial Analysis \\
\hline - Topographical & Reporting data (stats) & Map Composition \\
\hline - Land use & & Data Tabulation \\
\hline Assets & & \\
\hline - $\quad$ Property & & \\
\hline Data Sources: & Data Sources: & Data Sources: \\
\hline SG - Cadastral Data & $\begin{array}{l}\text { GPS assisted field } \\
\text { survey }\end{array}$ & Integrated GIS project \\
\hline $\begin{array}{l}\text { Aerial Photography - } \\
\text { land use }\end{array}$ & & \\
\hline $\begin{array}{l}\text { Data providers:- roads, } \\
\text { buildings, contours }\end{array}$ & & \\
\hline \multicolumn{2}{|l|}{ Data Processing } & $\begin{array}{l}\text { Information } \\
\text { Presentation }\end{array}$ \\
\hline \multicolumn{2}{|l|}{ Import GPS point data } & Maps \\
\hline \multicolumn{2}{|c|}{ Create polygon data from GPS point data } & Tables \\
\hline \multicolumn{2}{|l|}{ Database development } & \\
\hline \multicolumn{2}{|l|}{ Geo-rectification of CAD data } & \\
\hline
\end{tabular}

Table 3: Typical data needs and processing activities for disaster assessment 


\section{Conclusion}

It has been proven that in the absence of the data required for an analytical disaster assessment, a GIS project could be established within a relative short period of time, focussing on the affected area. The project made use of existing data and new data sets were created that could be used not only for mapping purposes, but to retrieve statistics related to impacts.

The value of the data is further illustrated by the fact that it can be used in the future for various purposes, including disaster risk assessment, land use planning and environmental management. The challenge is to test and validate this methodology and to promote it within the DRM fraternity. 


\section{References}

GUHA-SAPIR, D., BELOW, R. 2006. Collecting data on disasters: Easier said than done. Asian Disaster Management News. April - June 2006. Vol. 12 No. 2.

POOLMAN, J. 2006. Verbal communication with the author. Pretoria.

SMITH, K. 2001. Environmental Hazards. Assessing risk and reducing disaster. London and New York: Routledge.

SOUTH AFRICAN WEATHER SERVICE. 2005. Caelum Database. Electronic data obtained in Feb 2006. Pretoria.

AHEARN, S., ALMEIDA, D., GAHEGAN, M. (2006). Field Information Geospatialdatabase System (FIGS) for the United Nations Office for Coordination of Humanitarian Affairs (OCHA). Proof of concept and state of the art in FOSS Geospatial Technology. (Report prepared for the Technical Coordinator Field Information Support Project Office for the Coordination of Humanitarian Affairs. One UN Plaza DC1-1368 New York, NY 10017). 98 p. (Unpublished.) 